\title{
Effects of wogonoside on invasion and migration of lung cancer A549 cells and angiogenesis in xenograft tumors of nude mice
}

\author{
Yubo Yan, Lei Yao, Haobo Sun, Sainan Pang, Xianglong Kong, Su Zhao, Shidong Xu \\ Department of Thoracic Surgery, Affiliated Cancer Hospital of Harbin Medical University, Harbin 150000, China \\ Contributions: (I) Conception and design: Y Yan, S Xu; (II) Administrative support: Y Yan, L Yao, S Pang; (III) Provision of study materials or patients: \\ Y Yan, H Sun, X Kong, S Zhao; (IV) Collection and assembly of data: All authors; (V) Data analysis and interpretation: Y Yan, H Sun, S Pang, S Xu; \\ (VI) Manuscript writing: All authors; (VII) Final approval of manuscript: All authors. \\ Correspondence to: Shidong Xu. Affiliated Cancer Hospital of Harbin Medical University, 150 Haping Road, Nangang District, Harbin 150000, China. \\ Email: xushidongxsdd@163.com.
}

Background: Lung cancer is the most prevalent and deadly tumors around the world. Here we aimed to
investigate the effect of wogonoside (also called baicalin) on the invasion and migration of lung cancer A549
cells and angiogenesis in xenograft tumors in nude mice.
Methods: A549 cells of lung cancer were treated with different doses of wogonoside. After $24 \mathrm{~h}$, CCK8
was used to detect the survival rate of cells. The non-toxic doses of wogonoside $(0,10,25$, and $50 \mu M)$ were
selected for subsequent experiments. Transwell and scratch assays were used to detect invasion and migration.
The number of microtubule nodules was detected by microtubule formation experiment, and the expressions
of VEGF, E-cadherin, N-cadherin, and Vimentin were detected by Western blotting. BALB/c nude mice
were subcutaneously injected with lung cancer A549 cells to establish the xenograft model, followed by
intraperitoneal injection of $80 \mathrm{mg} / \mathrm{kg}$ of wogonoside. After 30 days, tumor volume was measured, and the
levels of VEGF and vimentin were detected with immunohistochemistry. The level of CD34 was determined
by flow sorting. Results: A549 cell survival decreased in a concentration-dependent manner, with the survival rate significantly reduced when the concentration of wogonoside exceeded $100 \mu \mathrm{M}(\mathrm{P}<0.05)$. A549 cell invasion and the number of microtubule nodules were significantly lower in the wogonoside $20 \mu M$ and the wogonoside $50 \mu \mathrm{M}$ groups $(\mathrm{P}<0.05)$ compared with the wogonoside $0 \mu \mathrm{M}$ group, while the rate of scratch closure and the protein levels of VEGF, N-cadherin, and Vimentin were all significantly reduced $(\mathrm{P}<0.05)$, and the expression level of E-cadherin was significantly increased $(\mathrm{P}<0.05)$. Compared with the control group, the tumor volumes of wogonoside $(80 \mathrm{mg} / \mathrm{kg})$ treated mice were significantly reduced after 30 days $(\mathrm{P}<0.05)$, and the levels of $\mathrm{VEGF}$ and vimentin positive cells were significantly reduced $(\mathrm{P}<0.05)$, as was the level of CD34 $(\mathrm{P}<0.05)$.

Conclusions: Wogonoside can inhibit the invasion and migration of lung cancer A549 cells and angiogenesis of xenograft tumors in nude mice.

Keywords: Wogonoside; lung cancer; invasion; migration; angiogenesis

Submitted Mar 19, 2020. Accepted for publication Apr 10, 2020.

doi: $10.21037 /$ jtd-20-1555

View this article at: http://dx.doi.org/10.21037/jtd-20-1555

\section{Introduction}

As the most common malignancy in the world, lung cancer is one of the leading causes of tumor-related deaths (1).
Lung cancer is divided into two subtypes: small cell lung cancer (SCLC), which accounts for approximately $15 \%$ of all lung cancers, and non-small cell lung cancer (NSCLC), which comprises the vast majority (approximately $85 \%$ ) of 
cases (2). Despite the significant advances in the diagnosis and treatment of lung cancer, including traditional surgery, chemotherapy, radiation therapy, and emerging target therapies and immunotherapy, these treatments fail to achieve a response in many patients. Tumor metastasis is also experienced by many lung cancer patients; and, together, these factors contribute to a poor prognosis. Therefore, there is still a vital need to find new therapeutic drugs for patients with lung cancer (3).

Natural products, especially plant-derived active agents, have assumed a core role in the development of new drugs. Wogonoside or baicalin, a biologically active flavonoid compound (4), is extracted from baicalensis root and possesses anti-cancer, anti-inflammatory, antiinflammatory, and angiogenic properties (5-7). Recent studies have reported wogonoside exhibits anticancer activity in a variety of cancer models, including breast cancer (8), leukemia (9), osteosarcoma (10), and colon cancer (11). However, to date, no research has been carried out to explore the effect of wogonoside on the occurrence and development of lung cancer. Therefore, this study investigated the effects of wogonoside on the invasion and migration of lung cancer A549 cells and angiogenesis in xenograft tumors in nude mice, to provide a theoretical basis for the usage of wogonoside in the clinical treatment of lung cancer.

We present the following article in accordance with the ARRIVE reporting checklist (available at http://dx.doi. org/10.21037/jtd-20-1555).

\section{Methods}

\section{Reagents and instruments}

Dulbecco's Modified Eagle's Medium (DMEM), fetal bovine serum (FBS) and trypsin were purchased from Invitrogen (Invitrogen, CA, USA). The bicinchoninic acid (BCA) kit was purchased from PIERCE (Rockford, IL, USA). Matrigel TM basement membrane matrix and transwell assay and artificial basement membranes were obtained from BD company (BD, CA, USA). Primary antibodies against VEGF, E-cadherin, $\mathrm{N}$-cadherin, and vimentin, and horseradish peroxidase (HRP)-labeled goat anti-mouse secondary antibody were obtained from Sigma (Sigma-Aldrich, St Louis, MO, USA). A high-speed low temperature centrifuge was purchased from Beckman (Beckman Coulter, CA, USA), and a $\mathrm{CO}_{2}$ incubator was purchased from Thermo Fisher Scientific (Waltham,
MA, USA). An electrophoresis chamber and a Trans-Blot Turbo Transfer System were purchased from Bio-Rad (Hercules, CA, USA). A FACSVantage SE flow cytometer was purchased from BD (BD, CA, USA), and a gel imaging system GDS-800 UVP from UVP (Upland, CA, USA).

\section{Cell culture}

A549 and HUVEC cells were cultured in DMEM medium supplemented with $10 \% \mathrm{FBS}$, at $37^{\circ} \mathrm{C}$ in an incubator containing $5 \% \mathrm{CO}_{2}$. When the cells reached a confluence rate of above $85 \%$, they were digested by $0.25 \%$ for passage.

\section{Detection of cell survival rate by CCK8}

Lung cancer A549 cells were treated with various doses $(1,2.5,5,10,25,50,100,200,300$ and $400 \mu \mathrm{M})$ of wogonoside, after being seeded in 96-well plates for $24 \mathrm{~h}$. After another 22 hours of culture, the cells were added with $10 \mu \mathrm{L}$ of CCK8 to each well in line with the manufacturer's instructions. After incubation for more $2 \mathrm{~h}$, a microplate reader was used to calculate absorbance in each group. A line chart was drawn, and the cell growth rate was calculated (multiplication factor $=$ cell absorbance $/ 0 \mathrm{~h}$ cell absorbance).

\section{Transwell assay to detect cell invasion}

Lung cancer A549 cells were randomly divided into 4 groups, which were treated with the doses of $0,10,25$, and $50 \mu \mathrm{M}$ (the wogonoside $0 \mu \mathrm{M}$, wogonoside $10 \mu \mathrm{M}$, wogonoside $20 \mu \mathrm{M}$, and wogonoside $50 \mu \mathrm{M}$ groups, respectively). Each group of cells was digested, centrifuged, and resuspended in serum-free DMEM medium at a density of $5 \times 10^{5}$ cells $/ \mathrm{mL}$, before $500 \mu \mathrm{L}$ of DMEM with $10 \%$ FBS was added to the upper chamber. After incubation at $37{ }^{\circ} \mathrm{C}$ and $5 \% \mathrm{CO}_{2}$ for $24 \mathrm{~h}$, the non-invasive cells and extracellular matrix gel were gently removed. The invading cells in the membrane were stained for $20 \mathrm{~min}$, washed with PBS, and then air dried. Five fields were randomly selected, and a microscope was used to count the number of invading cells on the membrane.

\section{Scratch assay to detect cell migration}

Before the experiment, five parallel straight lines were drawn on the back of a culture plate with a marker pen. Cells from each group were seeded in 12 -well plates, 
and a $10 \mu \mathrm{L}$ pipette was used to scratch straight lines perpendicular to the culture plate. The cells were then washed 3 times with warm PBS, and serum-free culture medium was added for culture. Photos were taken at $0 \mathrm{~h}$ and after $48 \mathrm{~h}$, and the width of the scratches was recorded. The rate of cell migration was calculated based on the changes in the width before and after the culture.

\section{Tubule-formation experiments}

To determine the angiogenic capacity of endothelial cells, a tubule-formation assay was performed in vitro. Precoated Matrigel ( $5 \mathrm{mg} / \mathrm{mL}, \mathrm{BD}$, USA) was solidified via incubation on a 48 -well plate at $37^{\circ} \mathrm{C}$ for $30 \mathrm{~min}$. The fused HUVEC cells were suspended in the culture medium at a density of $1.5 \times 10^{5}$ cells $/ \mathrm{mL}$ and incubated at $37{ }^{\circ} \mathrm{C}$ for $24 \mathrm{~h}$. Photographs were then taken with an Olympus DP71 immunofluorescence microscope and the number of microtubules was determined.

\section{Western blotting to detect VEGF, E-cadherin, $N$-cadherin, and vimentin expression}

The extraction of total protein from the treated A549 cells was carried out using lysis buffer. The protein concentration was then quantified with a BCA protein measurement kit. The sample containing $20 \mathrm{mg}$ of protein was separated by running $10 \%$ SDS-PAGE gel, before being transferred to a polyvinylidene fluoride (PVDF) membrane. The membrane was blocked with $5 \%$ skim milk at room temperature for $2 \mathrm{~h}$, and then incubated with primary antibodies against VEGF (1:1,000), E-cadherin (1:1,000), N-cadherin $(1: 1,000)$, and vimentin $(1: 1,000)$ at $4{ }^{\circ} \mathrm{C}$ overnight. The next day, the relative secondary antibody was added, and the membrane was incubated at room temperature for $1 \mathrm{~h}$. Finally, ECL reagent was added to detect the intensity of chemiluminescence corresponding to the target band with set exposure parameters.

\section{Animal experiments}

The animal experiments were approved by the Ethics Committee of Affiliated Cancer Hospital of Harbin Medical University and were carried out in strict accordance with the Guidelines for Animal Use in the National Institutes of Health. Six-week-old male BALB/ c null nude mice (purchased from Liaoning Changsheng Biotechnology, Liaoning, China) were used. Animals were housed in climate-controlled quarters with a $12 \mathrm{~h}$ light/ $12 \mathrm{~h}$ dark cycle and had free access to food and water. After acclimated for 2 weeks, $1 \times 10^{6}$ A549 cells with matrigel (BD Biosciences, San Jose, CA, USA) at 1:1 dilution were subcutaneously injected into the right flank region of all mice. After 5 days, 10 mice with xenografts were randomly divided into two groups and intraperitoneally injected with $80 \mathrm{mg} / \mathrm{kg} / \mathrm{d}$ of wogonoside or saline for 30 days as reported in previous research (12). Then the mice were anesthetized and sacrificed, and the samples were harvested for further experiments.

\section{Immunobistochemical detection of VEGF and vimentin}

Immunohistochemical staining of VEGF and vimentin in the tumor tissues was performed using a streptavidinbiotin-complex peroxidase kit. The slides were rinsed, dehydrated and mounted under a microscope to check and count immune response cells with the color as yellow to brown. The immunostaining was analyzed with an ImagePro Plus image analysis system connected to the Olympus microscope. At 400x magnification, cells with VEGE and vimetin-positive staining were quantified by counting the total number of yellow to brown cells in five randomly selected fields of view.

\section{CD34 content by FACS}

Blood was collected under sterile conditions and single cells were then isolated from peripheral blood. The samples from each group were diluted, centrifuged, and then cultured for $6 \mathrm{~h}$ so that unattached cells were discarded. The attached cells were considered peripheral blood mononuclear cells (PBMCs). PBMCs were collected, and then fixed and permeated. Anti-mouse CD34 FITC fluorescent monoclonal antibody was added to achieve full contact between the pellet and the antibody. The mixture was incubated for $30 \mathrm{~min}$ in the dark, and then centrifuged to retain the pellet. CD34 content was then immediately detected by flow cytometry.

\section{Statistical methods}

Statistical analysis was carried out with SPSS 21.0 (Chicago, IL, USA). Differences between groups were tested by $t$-test or one-way analysis of variance. Results were expressed as mean \pm standard deviation $(\bar{x} \pm S)$, and the difference was considered statistically significant with $\mathrm{P}<0.05$. 


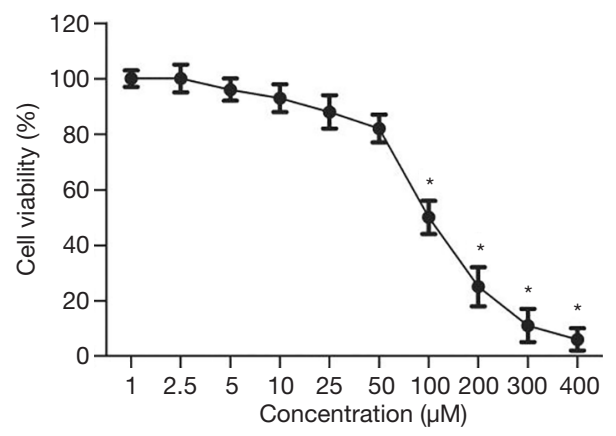

Figure 1 Changes in the survival rate of A549 cells. *, $\mathrm{P}<0.05$ compared with the wogonoside $0 \mu \mathrm{M}$ group.

\section{Results}

The effects of wogonoside at different concentrations on the viability of $A 549$ cells

The survival rate of A549 cells decreased in a concentrationdependent manner, after treatment with wogonoside at different concentrations for $24 \mathrm{~h}$ (Figure 1). When the concentration of wogonoside exceeded $100 \mu \mathrm{M}$, the survival rate of A549 cells was significantly lower than that of wogonoside at the concentration of $0 \mu \mathrm{M}(\mathrm{P}<0.05)$.

\section{The effects of wogonoside at different concentrations on A549 cell invasion and migration}

As shown in Figure 2, compared with the Wogonoside $0 \mu \mathrm{M}$ group, A549 cell invasion in the Wogonoside $20 \mu \mathrm{M}$ group and the Wogonoside $50 \mu \mathrm{M}$ group was significantly reduced $(\mathrm{P}<0.05)$, as was the rate of scratch closure $(\mathrm{P}<0.05)$.

\section{The effects of wogonoside at different concentrations on tubule-formation and VEGF expression}

As shown in Figure 3, compared with the wogonoside $0 \mu \mathrm{M}$ group, the number of microtubule nodules was significantly reduced in the wogonoside $20 \mu \mathrm{M}$ and the wogonoside $50 \mu \mathrm{M}$ groups $(\mathrm{P}<0.05)$. The expression level of VEGF protein in the wogonoside $20 \mu \mathrm{M}$ group and the wogonoside $50 \mu \mathrm{M}$ group was significantly lower than that in the wogonoside $0 \mu \mathrm{M}$ group, $(\mathrm{P}<0.05)$.

\section{The effects of wogonoside at different concentrations on epithelial-mesenchymal transition (EMT) in A549 cells}

As shown in Figure 4, compared with the wogonoside $0 \mu \mathrm{M}$ group, the expression level of E-cadherin protein in the wogonoside $20 \mu \mathrm{M}$ and the wogonoside $50 \mu \mathrm{M}$ groups was significantly increased $(\mathrm{P}<0.05)$, while the expression levels of $\mathrm{N}$-cadherin and vimentin in the wogonoside $20 \mu \mathrm{M}$ group and the wogonoside $50 \mu \mathrm{M}$ group were significantly reduced $(\mathrm{P}<0.05)$.

\section{The effects of wogonoside on angiogenesis in xenografts of nude mice}

To explore the effects of wogonoside in vivo, A549 cells were used to generate xenograft mice for 30-day treatment. As shown in Figure 5, compared with the control group, the tumor volume was significantly reduced after treatment with wogonoside at a dose of $80 \mathrm{mg} / \mathrm{kg}$ for 30 days $(\mathrm{P}<0.05)$. The results of immunohistochemistry showed that compared with the control group, the number of VEGF and vimentinpositive cells were significantly reduced after treatment with wogonoside $(\mathrm{P}<0.05)$. The results of flow sorting test showed CD34 content to be significantly reduced after treatment with wogonoside at $80 \mathrm{mg} / \mathrm{kg}$, compared with the control group $(\mathrm{P}<0.05)$.

\section{Discussion}

In recent years, significant progress has been made in studies on the molecular mechanisms of active ingredients of traditional Chinese medicine in tumor inhibition. The bioactivity of such ingredients includes the inhibition of tumor growth, the induction of apoptosis and cell differentiation, cytotoxicity, the regulation of cell signal transduction, multidrug resistance reversal, and the inhibition of telomerase activity $(9,12,13)$. In this study, lung cancer A549 cells were treated with different doses of wogonoside. After $24 \mathrm{~h}$, the A549 cell survival rate was reduced by bupivacaine in a dose-dependent manner. Therefore, bupivacaine doses without significant toxicity $(0$, $10,25,50 \mu \mathrm{M})$ were selected for subsequent experiments, to confirm the potential antitumor effect of wogonoside on lung cancer A549 cells.

Malignant tumor cells have the ability to migrate and invade to affect the surrounding normal tissues. Tumor metastases, in which invasion plays a core role, account for $90 \%$ of cancer-related deaths (14). During the invasion process, tumor cells first lose cell-to-cell connectivity, then degrade, restructure, and adhere to the surrounding extracellular matrix, before eventually migrating to distant sites through the extracellular matrix (15). Studies have 

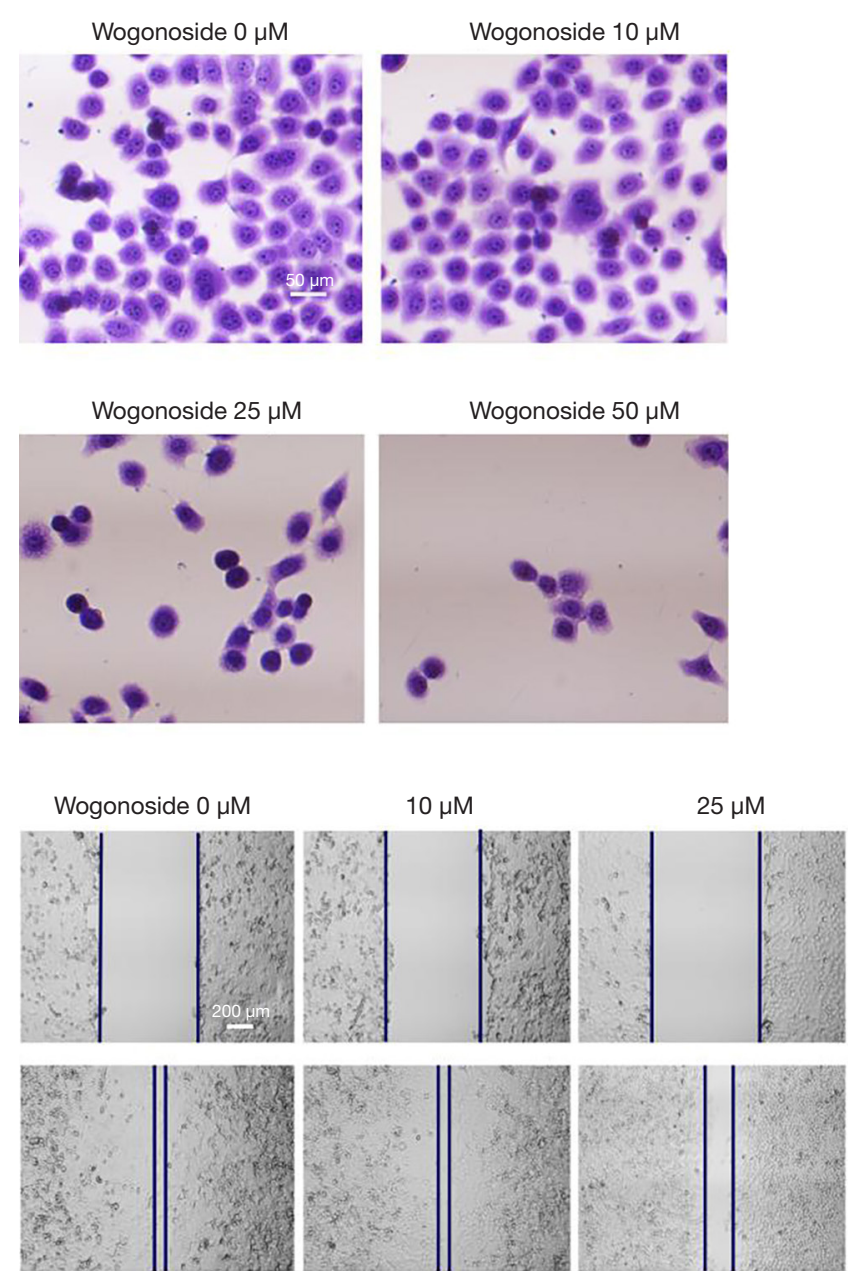

Figure 2 Changes in A549 cell invasion and migration after treatment with wogonoside at different concentrations. *, $\mathrm{P}<0.05$ compared with the Wogonoside $0 \mu M$ group.

confirmed that wogonoside can inhibit the invasion and migration of breast cancer cells, both in vitro and in vivo (8). This study showed that after treatment with wogonoside, the rate of A549 cell invasion decreased, as did the rate of scratch closure, which suggests that wogonoside might inhibit the invasion and metastasis of lung cancer A549 cells.

EMT occurs during the progression of epithelial tumors to increase the migration and invasion capacity of cancer cells. The process of EMT results in the downregulation of epithelial markers E-cadherin and upregulation of mesenchymal markers such as vimentin and $\mathrm{N}$-cadherin (16). Malignant cells have the ability to invade and metastasize during the EMT process. Previous studies have shown that the level of EMT is closely related to tumor aggression and recurrence, and a poor prognosis (17).
A study by Wei et al. found that wogonoside inhibits the EMT process in prostate cancer PC3 cells via the upregulation of the protein level of E-cadherin, and the downregulation of the protein expression levels of vimentin and $\mathrm{N}$-cadherin (18). The results of this study indicated that in A549 cells, after the treatment of wogonoside, the protein level of E-cadherin increased, while the expression levels of $\mathrm{N}$-cadherin and vimentin decreased, which was consistent with the results of Wei et al. (18). Comprehensive experimental results indicated that wogonoside can inhibit EMT in lung cancer A549 cells.

The occurrence and development of cancer are closely related to angiogenesis. As a key step in tumor development, angiogenesis is mainly triggered by chemotaxis and proliferative cytokines such as vascular endothelial growth factor (VEGF) (19). VEGF, which 

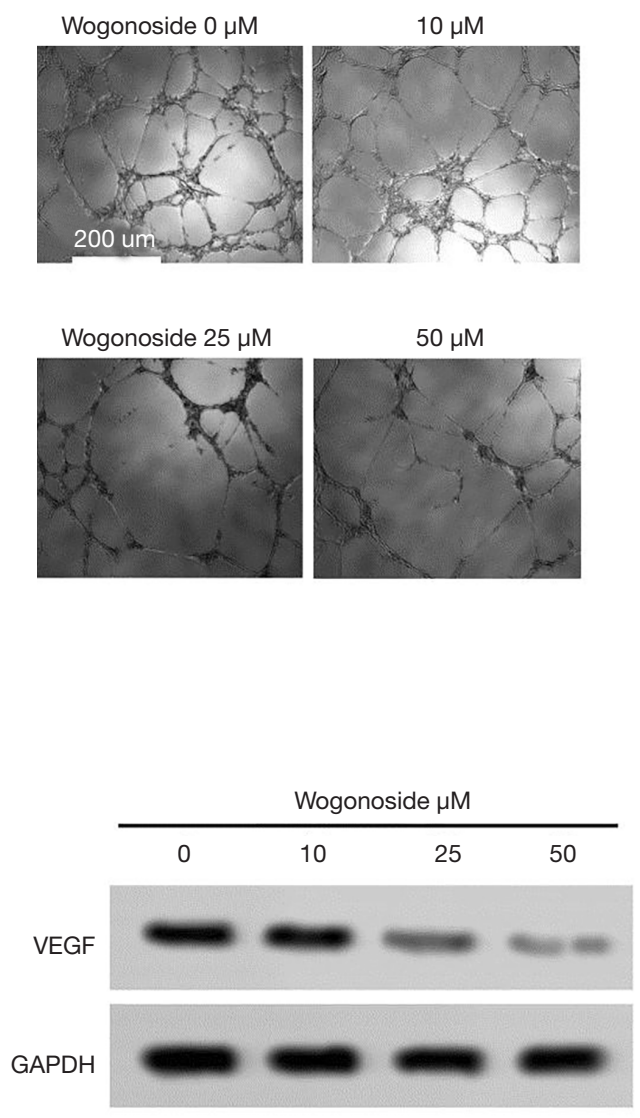
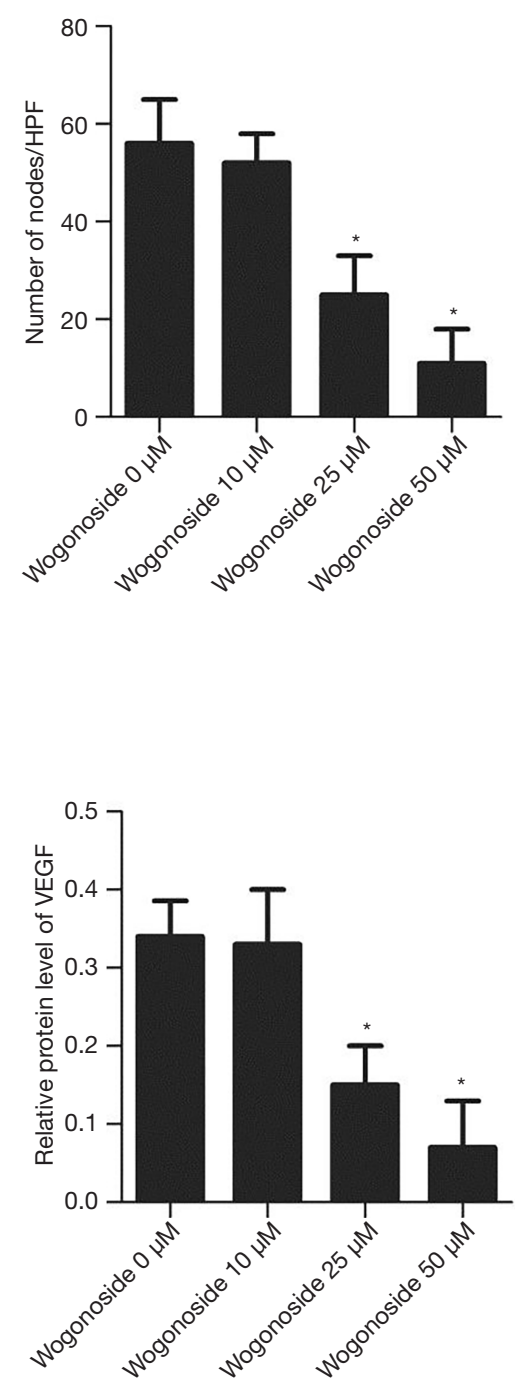

Figure 3 Changes in microtubules and VEGF expression after treatment with wogonoside at different concentrations. *, $\mathrm{P}<0.05$ compared with the Wogonoside $0 \mu \mathrm{M}$ group.

is mainly produced and released by tumor cells, is one of the most common regulators of angiogenesis, playing an important role in the regulation of tumor angiogenesis (20). Previous research has found that wogonoside inhibits angiogenesis in breast cancer via the inhibition of VEGF production in MCF-7 cells (12). Similarly, as a potential inhibitor of angiogenesis in the treatment of triple-negative breast cancer, wogonoside can inhibit angiogenesis in triple-negative breast cancer by reducing VEGF expression in vivo and in vitro (21). This study demonstrated that wogonoside treatment reduced tumor volume, decreased the number of VEGF and vimentin-positive cells, and reduced the content of CD34, which indicated that wogonoside could inhibit tumor growth and the invasion and migration of A549 cells; this suggests that wogonoside has an inhibitive effect on angiogenesis in xenograft tumors in nude mice.

In summary, wogonoside can inhibit the invasion and migration of lung cancer A549 cells and angiogenesis of xenograft tumors in nude mice, which may provide a theoretical basis for the usage of wogonoside in clinical treatment of lung cancer. 

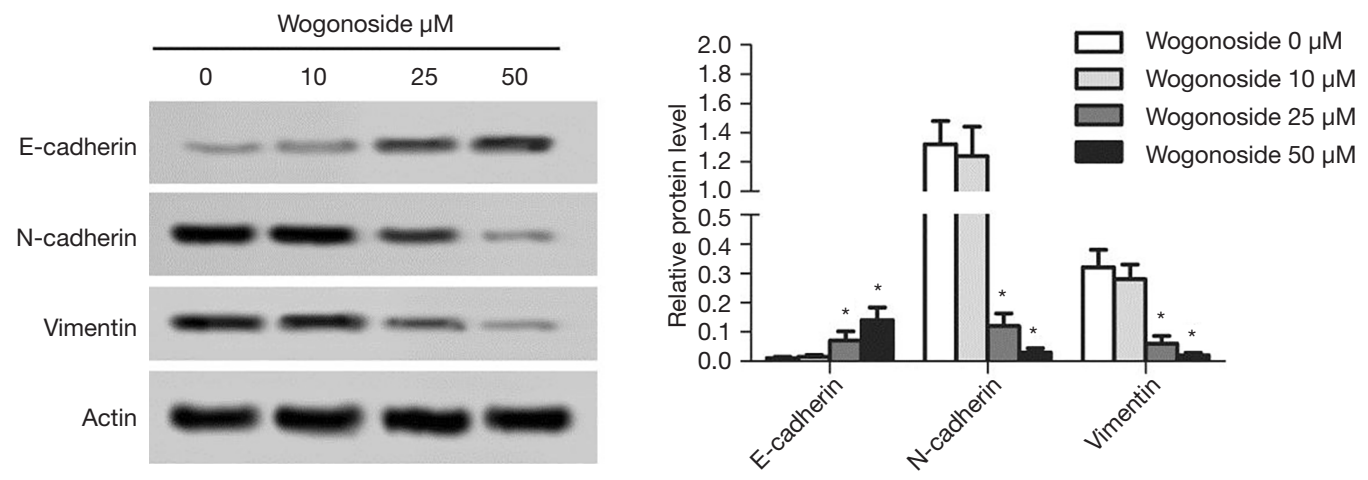

Figure 4 Changes in the expression levels of E-cadherin, N-cadherin, and vimentin after treatment with wogonoside at different concentrations. *, $\mathrm{P}<0.05$ compared with the Wogonoside $0 \mu \mathrm{M}$ group.

A

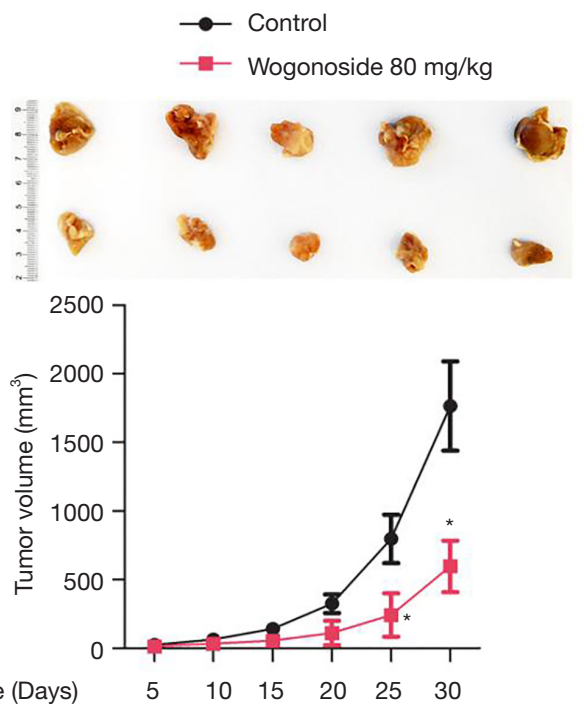

Time (Days)
B

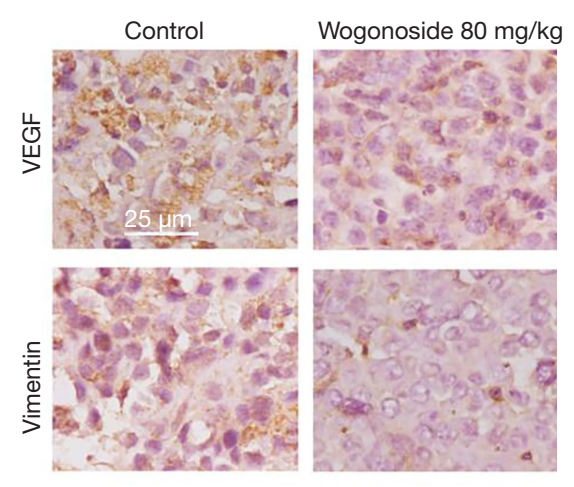

C

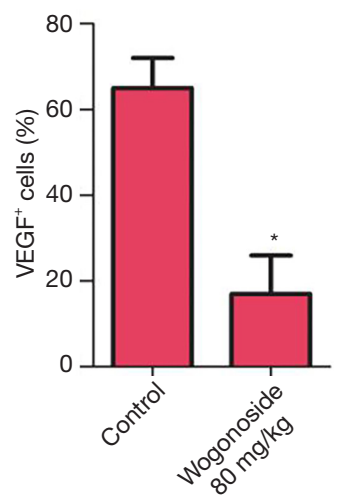

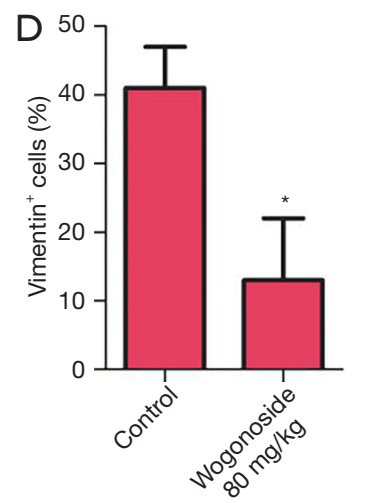

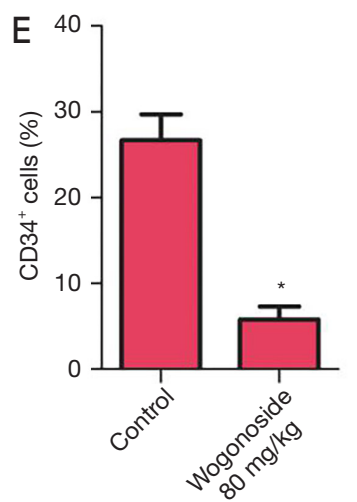

Figure 5 Effects of $80 \mathrm{mg} / \mathrm{kg}$ wogonoside in vivo. (A) Tumors at day 30 in both groups and changes in tumor volume during treatment. (B) Immunohistochemical staining of VEGF and vimentin, and immunohistochemical positive cells were counted for (C) VEGF and (D) vimentin. (E) CD34 content in PBMC tested with FACS after treatment. *, $\mathrm{P}<0.05$ compared with the control group. 


\section{Acknowledgments}

Funding: This work is supported by Heilongjiang Province Natural Science Foundation Project (LH2019H097). Haiyan Research Fund (JJQN2018-12).

\section{Footnote}

Reporting Checklist: The authors have completed the ARRIVE reporting checklist. Available at http://dx.doi.org/10.21037/ jtd-20-1555.

Conflicts of Interest: All authors have completed the ICMJE uniform disclosure form (available at http://dx.doi. org/10.21037/jtd-20-1555). The authors have no conflicts of interest to declare.

Etbical Statement: The authors are accountable for all aspects of the work in ensuring that questions related to the accuracy or integrity of any part of the work are appropriately investigated and resolved. The Ethics Committee approved the study of our center (No. KY2018-20).

Open Access Statement: This is an Open Access article distributed in accordance with the Creative Commons Attribution-NonCommercial-NoDerivs 4.0 International License (CC BY-NC-ND 4.0), which permits the noncommercial replication and distribution of the article with the strict proviso that no changes or edits are made and the original work is properly cited (including links to both the formal publication through the relevant DOI and the license). See: https://creativecommons.org/licenses/by-nc-nd/4.0/.

\section{References}

1. Torre LA, Bray F, Siegel RL, et al. Global cancer statistics, 2012. CA Cancer J Clin 2015;65:87-108.

2. Rykova EY, Ponomaryova AA, Zaporozhchenko IA, et al. Circulating DNA-based lung cancer diagnostics and follow-up: looking for epigenetic markers. Transl Cancer Res 2018;7:S153-70.

3. Shukuya T, Carbone DP. Predictive Markers for the Efficacy of Anti-PD-1/PD-L1 Antibodies in Lung Cancer. J Thorac Oncol 2016;11:976-88.

4. Li H, Hui H, Xu J, et al. Wogonoside induces growth inhibition and cell cycle arrest via promoting the expression and binding activity of GATA-1 in chronic myelogenous leukemia cells. Arch Toxicol
2016;90:1507-22.

5. Han C, Xing G, Zhang M, et al. Wogonoside inhibits cell growth and induces mitochondrial-mediated autophagyrelated apoptosis in human colon cancer cells through the $\mathrm{PI} 3 \mathrm{~K} / \mathrm{AKT} / \mathrm{mTOR} / \mathrm{p} 70 \mathrm{~S} 6 \mathrm{~K}$ signaling pathway. Oncol Lett 2018;15:4463-70.

6. Zhu Y, Zhu H, Wang Z, et al. Wogonoside alleviates inflammation induced by traumatic spinal cord injury by suppressing NF-kappaB and NLRP3 inflammasome activation. Exp Ther Med 2017;14:3304-8.

7. Lin B, Zhao K, Yang D, et al. Wogonoside impedes the progression of acute myeloid leukemia through inhibiting bone marrow angiogenesis. J Cell Physiol 2019;234:1913-24.

8. Yao Y, Zhao K, Yu Z, et al. Wogonoside inhibits invasion and migration through suppressing TRAF2/4 expression in breast cancer. J Exp Clin Cancer Res 2017;36:103.

9. Xiao R, Gan M, Jiang T. Wogonoside exerts growthsuppressive effects against $\mathrm{T}$ acute lymphoblastic leukemia through the STAT3 pathway. Hum Exp Toxicol 2017;36:1169-76.

10. Wang Y, Yin RF, Teng JS. Wogonoside induces cell cycle arrest and mitochondrial mediated apoptosis by modulation of Bcl-2 and Bax in osteosarcoma cancer cells. Int J Clin Exp Pathol 2015;8:63-72.

11. Sun Y, Zhao Y, Wang X, et al. Wogonoside prevents colitis-associated colorectal carcinogenesis and colon cancer progression in inflammation-related microenvironment via inhibiting NF-kappaB activation through PI3K/Akt pathway. Oncotarget 2016;7:34300-15.

12. Huang Y, Zhao K, Hu Y, et al. Wogonoside inhibits angiogenesis in breast cancer via suppressing Wnt/betacatenin pathway. Mol Carcinog 2016;55:1598-612.

13. Le X, Hanna EY. Optimal regimen of cisplatin in squamous cell carcinoma of head and neck yet to be determined. Ann Transl Med 2018;6:229.

14. Zeeshan R, Mutahir Z. Cancer metastasis - tricks of the trade. Bosn J Basic Med Sci 2017;17:172-82.

15. Friedl P, Wolf K. Tumour-cell invasion and migration: diversity and escape mechanisms. Nat Rev Cancer 2003;3:362-74.

16. Mittal V. Epithelial Mesenchymal Transition in Tumor Metastasis. Annu Rev Pathol 2018;13:395-412.

17. Odero-Marah V, Hawsawi O, Henderson V, et al. Epithelial-Mesenchymal Transition (EMT) and Prostate Cancer. Adv Exp Med Biol 2018;1095:101-10.

18. Wei C, Jing J, Zhang Y, et al. Wogonoside Inhibits Prostate Cancer Cell Growth and Metastasis via 
Regulating Wnt/beta-Catenin Pathway and EpithelialMesenchymal Transition. Pharmacology 2019;104:312-9.

19. Fallah A, Sadeghinia A, Kahroba H, et al. Therapeutic targeting of angiogenesis molecular pathways in angiogenesis-dependent diseases. Biomed Pharmacother 2019;110:775-85.

20. Siveen KS, Prabhu K, Krishnankutty R, et al. Vascular

Cite this article as: Yan Y, Yao L, Sun H, Pang S, Kong X, Zhao S, Xu S. Effects of wogonoside on invasion and migration of lung cancer A549 cells and angiogenesis in xenograft tumors of nude mice. J Thorac Dis 2020;12(4):1552-1560. doi: 10.21037/jtd$20-1555$
Endothelial Growth Factor (VEGF) Signaling in Tumour Vascularization: Potential and Challenges. Curr Vasc Pharmacol 2017;15:339-51.

21. Huang Y, Fang J, Lu W, et al. A Systems Pharmacology Approach Uncovers Wogonoside as an Angiogenesis Inhibitor of Triple-Negative Breast Cancer by Targeting Hedgehog Signaling. Cell Chem Biol 2019;26:1143-58.e6. 